\title{
Measuring Competitive Intelligence as a Case of North Cyprus Banks
}

\section{Mohammed $\mathrm{HZ}^{*}$ and Çiçek $\mathrm{O}$}

Girne American University, Cyprus

\begin{abstract}
One of the greatest characteristics of the present age is the widespread changes in the human knowledge along with the increasing number of social, political, economic, and technological disciplines. As a result, it is no longer the superior quality of products and services that is the recognizing and distinguishing factor but the quality of organization knowledge that is the key variable which determines its success. In addition, all kind of organizations need information for supporting decision making process at distinctive levels in order to become competitive at the global level and retain their positions through exploiting environment opportunities. In today's world, the use of information and its conversion to applied intelligence to leading organizational decision-making has attracted increasing attention and seems to be an obligation and compulsion. Competitive intelligence plays a central role in protecting organizations against future risks and ensuring perception of concealed opportunities. Accordingly, the banking sector in North Cyprus is pivotal in developing the economy of this wonderful island. Therefore, this study seems to be the first attempt to measure competitive intelligence among 64 employees at several Cypriot banks including Turkish IS, Garanti, Ziraat, TEB, and Near East. Using Knowledge and the application of descriptive statistics. The research findings denote that there is a high level of competitiveness among the employees from the banks selected for this study.
\end{abstract}

Keywords: Benefit of competitive intelligence; Competitive intelligence; Competitive intelligence process; Effective competitive intelligence

\section{Introduction}

Competition among economic and business organizations is growing at a rapid pace. In order to stay, compete, and survive in the highly competitive environment, all types of organizations need information in addition to new tools for decision making process. One of the central principles in modern management excellence. Fact- based management can be achieved through organization's access to information. In competitive environment for all types of organizations it is important that quick access to related information is available. To account for this need, a sundry of instruments are used in different organizations. Competitive intelligence is the art of planning, gathering, processing and saving information related to decision making and make it available for the whole organization and every individual at different levels in the light of their own needs [1]. Naturally, it is important for organizations to recognize and understand the competition in order to have the capacity to adapt to changing market and environmental trends. Competitive intelligence has the ability to distinguish organizations from one another, and be equally utilized to inform an organization about developing trends within the business [2]

\section{Literature review}

The ensuing paragraphs contains a succinct review or existing literature on competitive intelligence. It begins by providing a brief definition of competitive intelligence and continues with listing the benefits of competitive intelligence for organizations. Furthermore, the literature on what affects competitive intelligence is briefly reviewed, and the main processes of competitive intelligence are discussed. Finally, it is demonstrated that undertaking this research and its finding will fill an important gap in the literature.

\section{Competitive intelligence}

In a business competitive market, the organization's success increasingly depends on gaining a decent understanding of competitive planes and activities, and utilizing that understanding to distinguish one's own products and serves in a significant way. An ever growing number of organizations have invested in competitive intelligence in order to obtain knowledge about their competitors.

Competitive intelligence could be known as the process of selecting, gathering, and explaining general information by focusing on competitors' capabilities, performance, targets, and position. In this methodology, sporadic information about the competitors and customers is replaced by strategic applied knowledge in the field of organization's threats and opportunities [3]. Consequently, continuous analysis of the organization's internal and external environment as well as explanation of information obtained from the environment significantly impact on leadership's decisions to further the achievement of the organization [4].

Kahaner [5] underscores the need to recognize and distinguish between information and intelligence in organization: Information is accurate and factual. It includes numbers, statistics, scattered data about individuals and organization. Intelligence, on the other hand, is information that has been filtered and sifted, and analyzed. It requires knowing precisely the contrasts between information and intelligence. What managers need for decision making process is intelligence and not information.

Competitive intelligence prompts organizations in both private and state sectors to make sensible decisions about marketing, investment, market expansion, and product and serves development, R\&D and business approaches. To be effective, competitive intelligence must be legitimate and it must respect morality. The intelligence transfers outside knowledge to the company by adhering to specific rules and guidelines. Therefore, an alternative and more accurate definition of competitive intelligence can be "gathering information related

*Corresponding author: Hakar Zaki Mohammed, Girne American University, Cyprus, Tel: +90 392650 2000; E-mail: ha_amedy@yahoo.com

Received June 23, 2015; Accepted July 27, 2015; Published July 31, 2015

Citation: Mohammed HZ, Çiçek O (2015) Measuring Competitive Intelligence as a Case of North Cyprus Banks. Int J Econ Manag Sci 4: 275. doi:10.4172/21626359.1000275

Copyright: (C) 2015 Mohammed HZ, et al. This is an open-access article distributed under the terms of the Creative Commons Attribution License, which permits unrestricted use, distribution, and reproduction in any medium, provided the original author and source are credited. 
to competitors and environment to create and retain competitive intelligence". According to McGonagall and Walla [6], intelligence is a systematic process utilized by organizations to ensure updating the related and precise information of competitors. While Odenhaal [7] argues that competitive intelligence is a business process that, if managed successfully, leads to creation of organization efficiency. Additionally, CI could be utilized as an instrument for lessening operational risk. Organizational risk relates not just to its physical measurement but also to any environmental uncertainty. In summary, competitive intelligence is the best method to reduce uncertainty.

\section{Benefits of competitive intelligence}

Organizations with strong competitive intelligence programs have a superior understanding of the competitive landscape such as having a universal view to competitive threats and opportunities that helps organizations to understand and move more quickly toward devising and formulating strategies and plans in order to maximize competitive advantage $[8,9]$.

Competitive intelligence can have the characterizing effect in the outcome of products, services, acquisitions, marketing strategies, and technology development, etc. Specific benefits of competitive intelligence include [10]:

a. Improved productivity and profit, or leveraging of the organization's knowledge assets

\section{b. Early cautioning of competitive threats}

c. An extraordinary source of impartial news, truth and analysis relevant to strategic decision-making

d. Developing functional relationships throughout the organization

e. Provision of progressing linkages with security (and ideally counterintelligence), and

f. Reinforcement of a culture of competitiveness in the organization by concentrating on external threats and influences.

\section{Effective competitive intelligence}

According to Jaworski et al. [11], we can recognize four classes of variables that seem to impact the dimension of efficacy at the organizing, search and sense-making stages of the competitive intelligent process. The four classes of variables are.

Competitive intelligence network: Given the amount of informants provided for the nurturing and development of informal networks, it may not be surprising that a number of variables pertaining to the network itself seem to influence several dimensions of the competitive intelligence efficacy.

Business environment: The second class of variables pertains to how attributes of the internal and external environment influence the organizing, searching, and Competitive Intelligence through (recognition systems, time allocation, and market pressure).

Information environment: The information environment refers to the properties of the information confronted by the competitive intelligence analyst through (richness, and information value).

Analyst characteristics: Characteristics of the individual accused of creating competitive intelligence and the strategies they use to create it additionally seemed to influence the efficacy of the competitive intelligence. According to Day and Nedungadi's [12] investigator's characteristics have largely been overlooked in the literatures of strategy and marketing.

\section{Competitive intelligence process}

Viviers et al. [13] argue that the key critical areas of Competitive intelligence are planning and focus, collection, analysis, and dissemination (communication). During this research we focused on those four processes and tried to measure them among a sample of North Cyprus banks.

Planning: The first step in competitive intelligence process is planning and focus. This stage is necessary for the identification of the problem which will be solved through a competitive intelligence process. The planning step is not about gathering all the possible information. It is initially necessary to focus on particular information that is relevant to top-level management. That is to say, "identification of needs" must first be completed. This process is a vital part of the general process to avoid collection of irrelevant information [14].

Collection: During this procedure, information is gathered from an assortment of sources - primary as well as secondary. Primary sources of information involve suppliers, customers, government agencies, employees, etc., while secondary source include analyst reports, magazines, Internet website, TV, radio, etc. The choice of a particular source is directly related to the type of information focused. According to Rouach and Santi [4], the bulk of the information, amounting to $80 \%$ at times, needed to create intelligence is already introduced inside an organization, and that this information is not shared with the people who immediately require it due to organizational, geographic, or communication barriers.

Analysis: The most difficult part of the Competitive Intelligence process is analysis [15]. Organizations need to employ different analytical tools such as SWOT analysis to analyze information (Strength, Weakness, Opportunity and Threats) for competitor profiling and Porter's Five Forces Model, and PEST analysis (political, economic, social, and technological). These analytical models if applied correctly can change dissimilar information into actionable intelligence. The analysis stage will finished by creating some intelligence products which take the shape of documents and activities like: organization profiles, benchmarking, industry analysis, technology assessments, daily reports, strategic impact analysis, customer and supplier profiles [16].

Dissemination (Communication): Dissemination is the final step of the intelligence process in which the intelligence will is delivered to the customers of the competitive intelligence or to those who request it within the organization. According to Kahaner [5] there are more than one way to disseminate intelligence. These include newsletters, intelligence reports to presentations, and meetings with the customers to name a few. As a general rule, the competitive intelligence team or professional are expected to be prepared and arranged to defend their suggestions or actions with logical arguments, utilizing presentations and persuasive skills, and suitable format or media to every case.

\section{Research Methodology}

The research combines the qualitative and quantitative method. Two instruments were used to collect data, namely, a survey questionnaire and semi-structured interviews. The questionnaire focused on identifying and measuring the process of competitive intelligence. A descriptive case study of samples of bank employees at North Cyprus was conducted. The research population consisted 
of 64 employees at Turkish IS, Garanti, Zeraate, TEB, and Near East banks. Questionnaire findings were analyzed through the use of the SPSS program and the data were analyzed using Percentage, Mean, Frequency, and Std Deviation. The interview method was used to support the findings and to have a better understanding of competitive intelligence among a sample of North Cyprus banks.

\section{Significance of the research}

It is important to note that this research is expected to make a contribution to both the current bank practice and academic knowledge. Secondly, from the practical perspective, this study could be used to find opportunities for improving the level of competitive intelligence in the selected banks. This process will help bank managers to develop a better appreciation of the changeable environmental factors on this wonderful island, and encourage them to exploit potential opportunities and avoid current or futures threats.

\section{Research purpose}

The main purposes of this research are as follows:

a. To assess the level of competitive intelligence applied at North Cyprus banking sectors.

b. To assess the limitation in applying competitive intelligence at selected banks.

c. To help bank managers to better understand competitive intelligence and use it as a source for decision making process.

\section{Research questions}

A wide range of research has been conducted to measure and to develop competitive intelligence and its main process. However, few studies have focused on this important topic in North Cyprus. Accordingly, this study attempted to answer two critical questions.

a. What are the levels of competitive intelligence process among the sample of North Cyprus banks?

b. How we can improve the level of competitive intelligence and its four interrelated processes?

\section{Banking sector at north Cyprus}

The Turkish Republic of North Cyprus TRNC financial system consists of three types of banks (central, commercial, and investment).
The total share of the first ten banks was $79.21 \%$. Based on ownership, TRNC commercial banks can be divided into state, private and foreign banks. State banks control $29.48 \%$ of total assets as against $39.71 \%$ controlled by private banks. Foreign banks, on the other hand, control $30.81 \%$ of total assets [17]. Currently this island has a total of 15 national, 2 state-owned, and 7 foreign banks. In terms of bank branches, domestic banks have 171 branches in total while foreign banks have 47 branches.

\section{Data analysis and research findings}

1-General information about the study sample: Table 1 shows the demographic information about selected employees. Based on the data demonstrated in Table 1, the majority of respondents were female amounting to $56.3 \%$ while Males' share was $43.8 \%$. In addition, the data indicates that most respondents (35.9\%) fall into the 26-35 age group followed by the $36-45$ age group with $34.4 \%$. Those aged 25 or less ranked third constituting $17.2 \%$ of the total number. Finally, a meager $12.5 \%$ of respondents aged 46 years and above. Accordingly, it can be inferred that youths made up the majority of respondents $[18,19]$.

The data presented in Table 1 pertains to the respondents' level of education. While $29.7 \%$ of respondents had completed high school or less, the majority of the selected samples had bachelor's degree rating $40.6 \%$. The ratios for diploma and Masters/ $\mathrm{PhD}$ degree holders were were $18.8 \%$ and $10.9 \%$ consecutively.

In the sample consisting of 64 respondents, $50.0 \%$ had less than 5 years of work experience. Around $28.1 \%$ had worked between $6-10$ years while $21.9 \%$ had 11 or more years of work experience. The results show that majority of respondents had little work experience.

2- Measuring competitive intelligence: The researchers used descriptive statistics measurements to describe and measure the competitive intelligence between selected banks using (Mean, and Standard Deviation). A five-point Likert scale questionnaire was used to collect data. Table 2 demonstrate descriptive measurements related to competitive intelligence.

As shown in Table 2, the mean and S.D. for competitive intelligence obtained from 15 items were 3.928 and .937 respectively. According to tabulated data the highest means of 4.55 and 4.45 were obtained on Q14 and Q15 respectively. The relevant S.Ds was .733 for Q14, and .711 for Q15. That refers to the fact that banks leaders use collective information from other banks as a source in decision

\begin{tabular}{|c|c|c|c|c|c|c|c|}
\hline \multicolumn{8}{|c|}{ Study sample according to Gender } \\
\hline \multicolumn{4}{|c|}{ Female } & \multicolumn{4}{|c|}{ Male } \\
\hline \multicolumn{2}{|c|}{$\mathbf{F}$} & \multicolumn{2}{|c|}{$\%$} & \multicolumn{2}{|c|}{$\mathbf{F}$} & \multicolumn{2}{|c|}{$\%$} \\
\hline \multicolumn{2}{|c|}{36} & \multicolumn{2}{|c|}{56.2} & \multicolumn{2}{|c|}{28} & \multicolumn{2}{|c|}{43.8} \\
\hline \multicolumn{8}{|c|}{ Age of respondents } \\
\hline \multicolumn{2}{|c|}{25 and less } & \multicolumn{2}{|c|}{ 26-35 } & \multicolumn{2}{|c|}{$36-45$} & \multicolumn{2}{|c|}{46 and more } \\
\hline $\mathbf{F}$ & $\%$ & $\mathbf{F}$ & $\%$ & $\mathbf{F}$ & $\%$ & $\mathbf{F}$ & $\%$ \\
\hline 11 & 17.2 & 23 & 35.9 & 22 & 34.4 & 8 & 12.5 \\
\hline \multicolumn{8}{|c|}{ Education Levels for selected employees } \\
\hline \multicolumn{2}{|c|}{ High school or less } & \multicolumn{2}{|c|}{ Diploma } & \multicolumn{2}{|c|}{ Bachelor } & \multicolumn{2}{|c|}{ Master and over } \\
\hline $\mathbf{F}$ & $\%$ & $\mathbf{F}$ & $\%$ & $\mathbf{F}$ & $\%$ & $\mathbf{F}$ & $\%$ \\
\hline 19 & 29.7 & 12 & 18.8 & 26 & 40.6 & 7 & 10.9 \\
\hline & & & exper & r res & & & \\
\hline & d less & & & & & more & \\
\hline & & & & & & & \\
\hline & & & & & & & \\
\hline
\end{tabular}

Table 1: General information about respondents. 
Citation: Mohammed HZ, Çiçek O (2015) Measuring Competitive Intelligence as a Case of North Cyprus Banks. Int J Econ Manag Sci 4: 275. doi:10.4172/21626359.1000275

\begin{tabular}{|c|c|c|c|c|c|}
\hline $\mathbf{Q}$ & Mean & S.D & $\mathbf{Q}$ & Mean & S.D \\
\hline Q1 & 3.64 & 1.239 & Q9 & 3.02 & .917 \\
\hline Q2 & 4.34 & .859 & Q10 & 3.91 & 1.019 \\
\hline Q3 & 4.41 & .610 & Q11 & 3.84 & 1.130 \\
\hline Q4 & 4.19 & .889 & Q12 & 4.31 & 1.125 \\
\hline Q5 & 3.64 & .982 & Q13 & 4.03 & 1.069 \\
\hline Q6 & 3.78 & 1.061 & Q14 & 4.55 & .733 \\
\hline Q7 & 3.42 & .956 & Q15 & 4.45 & .711 \\
\hline Q8 & 3.39 & .769 & & & \\
\hline $\begin{array}{c}\text { Total } \\
\text { Average }\end{array}$ & & & & 3.928 & .937 \\
\hline
\end{tabular}

Table 2: Means and Standard Deviations for Competitive Intelligence.

making process to increase the validity and quality of decisions. Also based on results, it can be inferred that TRNC banks initiate marketing and communication effort to create positive relationship with other banks. Table 2 also shows that lowest means equaling 3.02 and 3.39 were obtained on Q9 and Q8. The relevant SDs for Q9 and Q8 were .917 and .769 respectively. These results point to the fact that it may be possible to measure bank employees' perception of what competitive intelligence is. However, banks don't try to hire people or other banks at TRNC to collect information on their behalf which is the clear evidence that completive intelligence at selected banks is still an ethical issue.

\section{Conclusions and Recommendations}

Competitive intelligence is a business instrument that assists all kind of organizations during strategic management processes and developing business performance through improving organization and employees' knowledge, in addition to enhancing internal and external communications. It leads organization successfully in uncertain situations at changeable competitive environments. Through this process organizations are able to forecast their markets and develop them through analyzing competitors' behavior and actions.

This research is in support of the fact that competitive intelligence and its main processes and practices have serious implications on banks performance. Through interviews with employees it was observed that the biggest limitation and threat is how to deal with other banks' plan and actions, and how we can exploit unrecognized opportunities through using available resources. Based on the findings of this research, the following outcomes and suggestions are listed:

a. Even the selected banks and its managers began to use competitive intelligence, but still there is a barrier in understanding what is competitive intelligence about and how we can exploit it to obtain organizations objectives.

b. We recommend selected banks to use a variety of resources (primary and secondary) in their decision making process.

c. The research recommends banks to organizea special training course for employees to acquaint them with competitive intelligence and its process.

d. We recommend selected banks to use most updated methods (Internet, social media, TV, newspaper, etc.) in order to communicate and explain their future projects and plans, as well as collecting relevant information from other banks.

e. We recommend banks to take into consideration customer feedback and develop customer relationship management (CRM) to collect important information which in turn will help them to have clear intelligence regarding their customer.

\section{References}

1. Mejarshin AS (2013) Competitive intelligence, Competitive advantage in the success business organizations. Reef Resour Assessment Manage Tech Pap 38: 2 .

2. Johns P, Van DD (2010) Competitive Intelligence in service marketing: a new approach with practical application. Market Plan 28: 551-570.

3. Albescu F, Pugna I, Paraschiv P (2009) Business Competitive Intelligence The Ultimate Use of Information Technologies in Strategic Management. Bucharest Acad Econ Stud.

4. Rouach D, Santi $P$ (2001) Competitive Intelligence Adds Value: 5 Intelligence Attitudes. Eur Manage J1 9: 552-59.

5. Kahaner L (1996) Competitive intelligence - how to gather, analyze, and use information to move your business to the top. Simon \& Schuster, New York.

6. McGonagall JJ, Walla CM (1999) The intelligence age of competitive group Inc, Westport, ct.

7. Odenhaal B (2003) Competitive Intelligence-Key to Corporate Risk Management. J Secur Oper Risk Manage.

8. Vedder RG, Vanecek MT, Guynes CS, Cappel JJ (1999) CEO and CIO perspectives on competitive intelligence. Commun ACM 42: 109-16.

9. Wright S, Calof JL (2006) The Quest for Competitive, Business and Marketing Intelligence, A Country Comparison of Current Practices. Eur J Market 40: 453-465.

10. Bernhardt D (2003) Competitive Intelligence. How to acquire and use corporate intelligence and counter-intelligence. Prentice Hall. Financ times 88-89.

11. Jaworski, BJ, Macinnis DJ, Kohli AK (2002) Generating Competitive Intelligence in Organizations. J Market-Focused Manage 5: 279-307.

12. Day G, Nedungadi P (1994) Managerial Representations of Competitive Advantage. J Market 58: 31- 44.

13. Viviers W (2002) Competitive Intelligence practices: a South African study. South African J Bus Manage 33: 27-37.

14. Strauss AC (2008) Competitive Intelligence Skills Needed In South Africa Unpublished Master thesis. University of Johannesburg.

15. Toit ASD (2003) Competitive intelligence in the knowledge economy: what is in it for South African manufacturing enterprises?. Int J Inform Manage 23 $111-120$

16. Nasri W (2012) Conceptual Model of Strategic Benefits of Competitive Intelligence Process. International J Bus Commerce 1: 6

17. Karavelioglu AM (2013) Analysis of Leadership Styles in Banking Sector in TRNC. Unpublished thesis. Girne American University.

18. Govoreanu A, Mora A, Serban A (2010) Competitive Intelligence. Stud Bus Econ 5: 101-107.

19. Calof JL (2008) Competitive Intelligence A practitioner academic and interdisciplinary perspective. Eur J Market 42: 717 -730. 